\title{
OPS PRICE CONTROL STANDARDS $†$
}

\author{
SAUL NELSON**
}

\section{INTRODUCTION-RELATION TO OPA STANDARDS}

To a considerable extent, OPS policies and standards drew upon the experience of its wartime predecessor, the Office of Price Administration, ${ }^{1}$ including the very important decision that explicit policies and standards were indispensable for sound and effective administration. However, OPS standards differed from those employed by OPA in many significant respects, both because OPA experience indicated the need for change and because of the very considerable difference in economic and political conditions.

The availability of the OPA background in this respect was both an advantage and a handicap. It was an advantage for the obvious reason that much of the preliminary spade work had been done so that the job of formulating and applying policies and standards did not have to start from scratch. It was a handicap in that it tended to direct policy formulation into the patterns made familiar by OPA and, consequently, to restrict and delay the exploration of new approaches to the problems which developed.

Moreover, OPS operated under conditions which differed in many important respects from those which had confronted its wartime predecessor. In the first place, the onset of wartime inflation was much less abrupt than that following Korea. In I940 there was a large volume of unemployed resources, and the initial impact of price increases was largely confined to the commodities directly affected by the war in Europe. Price pressures spread only gradually; consequently wartime price controls started from selected regulations covering a limited number of commodities and were progressively extended to cover the entire economy. The fact that there had been time for this gradual approach resulted in a reasonably balanced price structure at the time OPA imposed its general freeze at the end of April, 1942. In the case of OPS, on the other hand, the much more rapid inflationary price rise that preceded across-the-board action resulted in the freezing of a highly distorted price structure and made prompt action to remedy these distortions imperative. The development of policies appropriate for this purpose was a long and difficult task and one for which OPA experience offered inadequate guideposts.

In the second place, most OPA standards and policies were adapted to the acute general inflationary pressures which persisted through most of that agency's life and were consistent with, and supported by, the "hold-the-line" order issued by

TTe views herein expressed are the author's and do not necessarily reflect the position of any past or present Government agency.

* Former Director of the Office of Economic Policy, OPS.

${ }^{1}$ For a detailed analysis of OPA standards, see D. F. Cavers, Reed Dickerson, and Others, Prodlems in Price Control: Pricing Standards, Gen. Pub. No. 7, OPA Historical Reports of Wan AdMINistration (r947). 
President Roosevelt in April, I943. Rigid application of these standards was facilitated by the wartime psychology. In contrast, soft spots began to appear in some markets soon after OPS issued its general freeze and during subsequent months this "mixed market" situation spread progressively. There was no all-out war to generate public support for a really tough program; consequently, standards could neither be drawn as tightly nor applied as rigidly as had been possible under OPA. And it is doubtful whether such a tough program would have been justified, even if there had been public psychology to support it.

Despite these important differences, OPS found that many of the OPA standards, appropriately modified, did give workable answers to a large proportion of the problems which arose. While this does not mean that more radical modifications or even completely new approaches might not have worked equally well or perhaps better, it does indicate that the basic problems encountered by any price control program bear a marked similarity despite major differences in the underlying economic situation.

It is clear, for example, that price control officials will always be confronted with the problem of deciding whether a general increase in prices is justified for a particular industry and how much such an increase should be. It does not necessarily follow that the best answer to this question is to be found in an Industry Earnings Standard of the kind used by OPA and OPS, though some form of earnings test would almost surely have to be applied.

Similarly, problems will arise with respect to price adjustments for specific products or product lines and for individual firms or groups of firms. Answers to these problems will have to be found, though there may be better answers than those provided by the Product Standard for product lines or by the individual relief standard for firms or groups of firms.

Since it is likely that any future price control program will be associated with some form of national mobilization, provision would also have to be made to avoid interference with essential supply. Finally, policies would also have to be established to permit the orderly termination of controls when the emergency which requires them is over.

Obviously, the policies and standards adopted in any future price control program should not be automatically patterned after those which have been used with more or less success in the past. They would have to be adapted to the conditions then prevailing and to the legislative authority under which they operate. But, while the experience of the past may not offer the best answers to the problems of the future, it can at least indicate the nature of many of the issues which will arise and the merits and faults of the courses which were adopted.

\section{Why Standards Are Needed}

The administration of price control in the huge and complex American economy calls for the issuance of hundreds of general price regulations, thousands of amendments to such regulations, and literally tens of thousands of individual actions 
establishing or modifying specific prices for individual firms or groups of firms. Every one of these actions has a direct and significant impact on the operations and profits of at least some companies. Taken together, these actions have a profound effect upon business, upon production, and upon the stability of the economy as a whole. Standards are needed both to protect the rights of the individual firm or industry and to promote the success of the over-all program.

The task of formulating these regulations, amendments, and individual price actions must be done by a large number of officials of different backgrounds and prejudices and of varying degrees of experience and competence. In the absence of fairly explicit guides, it would be impossible to expect any consistent approach to the problems presented. Some officials would tend to be too generous; others too rigid. Prices for some industries and firms would be set too high to be consistent with sound stabilization; others would be set so low as to impose serious hardship or to interfere with production. In the absence of agency-wide OPS standards, businessmen would have had no way of knowing whether they were being fairly and consistently treated, orderly administration would have been impossible, and the agency's actions would have been subject to constant and proper challenge in the courts.

Thus, on April 16, I952, Mr. Ellis Arnall, then Director of the Office of Price Stabilization, made the following statement before the Senate Committee on Labor and Public Welfare in connection with the pending request of the steel industry for a price increase in excess of that allowable under OPS standards:

In order to decide which requests for price increases should be granted and which should be denied, we must have rules by which we can say "no" to some demands for price increases, and "yes" to others. Without such rules, price control could not operate. If price increases were permitted because the people in an industry were "gentlemen," or belonged to the right political party, or because they screamed the loudest, government by law would have disappeared, and freedom and individual rights would have perished.

In this connection, the Defence Production Act ${ }^{2}$ specifically provided that every action, regulation, or order "shall be accompanied by a statement of considerations involved in the issuance of such regulation or order." (Sec. 402-c). This requirement was patterned after that contained in the Price Control Act of $1942,{ }^{3}$ which constituted at the time an innovation in American administrative law. ${ }^{4}$ While this provision did not constitute a requirement that all actions taken by the agency conform with established and stated policies and standards, it is clear that a Statement of Considerations always stood on much firmer ground when it could be described as a specific application of an agency-wide rule.

At least equally important with the need for equitable and even-handed treatment was the need for standards in order to facilitate the success of the program as a whole. The total effect of price control is represented by the sum of the actions

${ }^{2} 64$ STAT. 798, 803 (1950), 50 U. S. C. App. \$2102(c) (Supp. x952).

${ }^{3} 56$ Srat. 24 (1942), as amended, 50 U. S. C. App. \$902 (1946).

- Cavers and Dickerson, op. cit. supta note $\mathrm{r}$, at I3. 
taken with respect to individual industries, commodities, and companies. Experience has repeatedly demonstrated the great difficulty of isolating the impact of price increases in any important sector of the economy, as illustrated by the problems OPS encountered following the steel price-wage settlement in August, I952. Even in the case of commodities or industries of lesser importance, price increases have a strong tendency to spread and to generate cumulative pressures in other fields. Pressures for unnecessary and unjustified price increases can only be resisted effectively when there are clearly defined ground rules setting forth when and to what extent such increases may be granted. In fact, the life of operating officials would have been rendered immeasurably more difficult had they not been able to support their resistance to unjustified demands for price increases by referring to the limitations imposed upon them by the applicable policy or standard.

On the other hand, it should be recognized that the issuance of administrative standards and policies has the inevitable effect of reducing flexibility of action. Even the Director himself is necessarily bound by the policy he has established for the guidance of his staff. A clear breach of standards in any case, no matter how meritorious, imperils the continued maintenance of the standard; a series of such breaches would render the standard untenable. The fact that OPS standards were made public as a matter of policy enhances the difficulties in this regard.

On balance, nevertheless, it is clear that the advantages of having explicit standards far outweigh their disadvantages. Consequently, OPS very early decided that it would follow the precedent established by OPA in the interest of sound, evenhanded, effective administration.

\section{Standards Contained in the Law}

The Office of Price Stabilization derived its authority from the Defense Production Act of $195^{\circ}$ and its subsequent Amendments in $195 \mathrm{I}$ and $1952 .{ }^{5}$ This Act established certain standards for the agency's operations and certain limitations on the exercise of its authority. These standards and limitations varied considerably in the degree to which they supplied precise guides for the agency's operation, though the limitations were, of course, more specific by their nature than the general standards.

Thus, Section 40 I (50 U. S. C. App. \$2ror (Supp. I952)) set forth the basic purposes of the Act; Section 402(a) (50 U. S. C. App. \$2I02(a) (Supp. I952)) authorized the President to promote voluntary action to further these objectives; and Section 402(b) (50 U. S. C. App. \$2102(b) (Supp. I952)) established the conditions under which selective ceilings could be imposed.

Section 402(c) (50 U. S. C. App. \$2r02(c) (Supp. I952)) established certain general criteria. In particular, it directed the President, so far as practicable to "ascertain and give due consideration to comparable prices ... which he finds to be representative of those prevailing during the period from May 24, r950 to June 24, I950,

${ }^{5} 64$ Stat. 798 (r950), as amended, 65 Stat. I3I (I95I), as amended, 66 StaT. 296 (I952), 50 U. S. C. App. \$206r (Supp. 1952). 
inclusive." It also stated that "in determining and adjusting ceilings . . . he [the President] should give due consideration to such relevant factors as ....: Speculative fluctuations, general increases or decreases in cost of production, distribution, and transportation, and general increases or decreases in profits . . . subsequent to June 24, $x 950 . "$

Obviously, none of these general instructions could, by themselves, furnish even an approximate answer as to the level at which price ceilings should be set aside or when and how they should be modified or adjusted. Perhaps the nearest thing to a specific instruction contained in these sections was that in Section 402(c) just described, but this paragraph indicated neither the extent of the consideration to be given within the limits of "practicability" to prices in the pre-Korean month nor the nature of the allowance to be made for changes in conditions since that period.

The broad requirement in Section 402(c) that price ceilings be "generally fair and equitable" was the same as that contained in OPA enabling legislation. It was clearly up to the agency, however, to define the meaning of fairness and equity on a basis which would conform with the intent of Congress and which would be acceptable to the courts. (Presumably the courts might expect that, in the absence of clearly distinguishing circumstances, the OPS interpretation of this phrase should draw on the OPA precedent.)

In addition to these very broad provisions, the Act and its subsequent amendments contained a considerable number of more specific directives. Among the more important of these were the following:

I. Section 402(d) (3) (50 U. S. C. App. \$2102(d) (3) (Supp. 1952)) of the Act set forth detailed rules regarding the minimum levels at which ceiling prices for agricultural commodities could be established. It also provided that ceilings for commodities "processed or manufactured in whole or substantial part from any agricultural commodity" could not be established or maintained below levels which would reflect to the farmer a price at least equal to the minima set forth in the Act. Subsequent amendments further restricted the discretion of the agency with respect to agricultural prices.

2. Section 402(d) (4) of the Act, the so-called Capehart Amendment of July, I95I, ${ }^{6}$ limited OPS authority with respect to price rollbacks and permitted individual sellers to obtain adjustments in their ceiling prices on the basis of their preKorean prices adjusted for all cost increases up to July 26 , $195 \mathrm{I}$ other than those which "the President may determine to be unreasonable or excessive."

3. The Herlong Amendment of $195 \mathrm{I}^{7}$ provided that no regulation "shall hereafter be issued ... which shall deny to sellers of materials at retail or wholesale their customary percentage margins over costs of the materials during the period May 24, I950 to June 24, I950." In 1952, this rule was further amended ${ }^{8}$ by making it applicable to all regulations previously issued.

\footnotetext{
'65 Stat. ${ }^{34}$ (I95I), 50 U. S. C. App. \$2102(d) (4) (Supp. 1952).

76 STAT. I34 (r95I), 50 U. S. C. App. \$2102(k) (Supp. 1952).

${ }^{8} 66$ STAT. 296 (1952).
} 
Provisions of these kinds were, of course, considerably more specific than those setting forth the purpose of the Act, the general conditions under which ceilings might be imposed, or the broad requirement of fairness and equity. Nevertheless, they still left considerable room for interpretation.

For example, the rule that ceilings for commodities produced from agricultural products must reflect at least the minima set forth for farmers in the Act raised a long series of difficult administrative questions, such as the magnitude of the margins to be preserved between the raw product and the processed item, the consideration that should be given to the value of inventories in the hands of processors during periods of changing prices, and, very importantly, the price relationships which should be maintained between the joint products of a single agricultural commodity. The difficulties of this last problem were enhanced by the fact that market conditions frequently make it impossible for processors to realize the established ceilings for some of these joint products, while ceilings for others could be obtained. Issues of this kind arose in connection with such items as beef and cattle by-products and oil and meal from oilseeds (particularly soybeans).

In connection with the Capehart Amendment, it was necessary to determine what costs were to be regarded as "unreasonable or excessive," to prescribe the manner in which cost increases up to July 26 , I95I were to be computed, and to determine the extent to which individual segments of a manufacturer's operation could be considered in isolation. It was also unclear as to whether the amendment applied to distributors. The agency took the position that it did not, but was reversed by the courts. Subsequently, however, a further amendment to the Act in $1952^{2}$ cleared up this ambiguity by supporting the agency's initial interpretation of the Congressional intent.

While the objective of the Herlong Amendment was clear, it, too, raised many questions of interpretation. As will be shown below, the concept of "customary percentage margins over cost" was peculiarly difficult to define.

In all such cases, therefore, it was necessary for OPS to interpret the precise meaning and intent of these statutory provisions and to develop rules for their application. Obviously, such rules had to be as nearly uniform as practicable. Thus, in the case of the Capehart Amendment, to mention one example, it would have been clearly inappropriate to permit arbitrary differences in the ways in which cost increases were computed by different industries or companies, or to accept a particular kind of cost increase as valid with respect to one seller while regarding it as "unreasonable or excessive" in relation to another seller.

Finally, the Act exempted a considerable number of commodities and services from control and this list was successively expanded in $195^{1}$ and $1952 .{ }^{10}$ In most cases, the language of the Act, in defining these exemptions, was sufficiently precise for direct application, as, for example, when it exempted "books, magazines, mo-

${ }^{\circ}$ Ibid.

${ }^{10} 64$ Stat. 803 (I950), 65 STAT. 134 (195I), 66 STAT. 296 (I952), 50 U. S. C. App. \$2102(e) (Supp. 1952). 
tion pictures, periodicals, or newspapers" and "prices charged and wages paid for services performed by barbers and beauticians." Even in the case of exemptions, however, there were some problems which required interpretation. Thus, the 1952 Amendment provided that "no ceiling shall be established or maintained under this title for fruits or vegetables in fresh or processed form." While it was perfectly clear that this prohibited the maintenance of price ceilings on canned vegetables, it was less clear whether it applied also to such items as canned vegetable soup or jams and jellies.

\section{OPS Administrative Standards}

It is evident, therefore, that the standards contained in the Act were not, and could not, in general, be sufficiently detailed to indicate the levels at which price ceilings should be established or when such ceilings should be modified for an industry, a firm or a commodity. Administrative policies and standards were needed to supply such guidance. These standards took a variety of forms. Some were included in "Price Operations Memoranda" issued by the Director of Price Operations. Others were incorporated in General Overriding Regulations, and some were included in specific Ceiling Price Regulations. The provisions in these regulations were usually supplemented and made more detailed in Price Oprating Instructions issued for the guidance of the officials responsible for administering them. The form was, however, secondary; they all had the same purpose of providing ground rules as precise as possible for the exercise of the price control authority.

The most urgent problem which confronted the agency immediately after the issuance of the General Ceiling Price Regulation was that of remedying the distortions which resulted from the freeze. The circumstances under which prices had been frozen resulted in inordinately high ceiling levels for some commodities and services, and in levels for others so low as to result in severe hardship and to threaten interference with continued production and distribution.

The nature of the policies adopted to remedy these distortions can best be described in relation to the different kinds of problems presented by the distributive trades, imported commodities, manufactured goods, and services.

\section{A. The Distributive Trades}

The difficulties in the case of the distributive trades were due largely to the inevitable lag between the movements in prices charged by producers and those charged by wholesalers and retailers. Fortunately, the availability of the OPA experience made it possible to act promptly in this field. Regulations were accordingly issued in rapid succession establishing ceiling prices for a large segment of non-food retailing and for most food retailing and wholesaling on the basis of current invoice costs plus normal distributive margins. These regulations were closely patterned after those which had been issued by OPA and, as a result, some of the margins established were based upon fairly old data. While this resulted in some difficulties 
and probably in some inequities, these regulations proved generally workable and were retained with only minor modifications to the end of the control period.

Additional regulations were issued gradually covering the remainder of the wholesale and retail fields. For the most part, these conformed to the basic pattern employed in the earlier actions, though the precise nature of each regulation was adapted to the specific situation involved. In the case of beef retailing and wholesaling, for example, specific dollars-and-cents ceilings were established, but these were based upon livestock ceiling prices prevailing at the time and normal distributive margins. The use of dollars-and-cents ceilings was necessary because of the administrative difficulties involved in the use of the straight margin technique. It was felt that the administrative advantages of spelled out dollars-and-cents prices more than compensated for the fact that ceilings would not be automatically reduced as primary market prices fell. Upward adjustments would not be needed as long as livestock ceilings were unchanged.

In the case of most non-food wholesaling, Supplementary Regulation $29^{11}$ to General Ceiling Price Regulation permitted, in effect, a one-time adjustment of prices to restore normal margins where these had been squeezed under the freeze. Further increases were permitted or decreases required only in a limited number of special cases. The complexity of the situation in this field was such that the continued readjustment of ceiling prices to conform with changing purchase costs did not seem practical or appropriate.

In its broadest aspects, the standard implied in these regulations was therefore a fairly simple one. In general, it meant that prices charged by retailers and wholesalers would be permitted to fluctuate with their purchase costs on a basis which would preserve, as far as possible, their customary distributive margins.

For a considerable period of time, however, one basic issue of principle remained unsettled. If distributive margins were maintained at the same percentage over cost, their magnitude in dollars-and-cents would, of course, increase as the cost of the commodities rose. At the same time, the operating costs of many distributors were also rising to some extent, reflecting such factors as higher wages, rentals, and utility rates as well as increased financial carrying charges due to the rising costs of the merchandise. In some distributive trades such as the metals trades, such changes in operating costs were relatively unimportant and, as a result, the normal practice in these trades has been to mark up merchandise by a uniform dollars-andcents amount rather than by a customary percentage. In most consumer goods fields, however, this increase in operating costs was significant, and markups in those trades are usually calculated in terms of percentages.

Early OPS policy, however, did not accept the maintenance of customary percentage margins in all such cases as an invariable rule. The rise in prices since Korea had widened dollars-and-cents margins substantially, and it was felt that in some cases, at least, distributors should not be allowed to "mark up" further in-

\footnotetext{
${ }^{11}$ I6 Fed. REg. 501 I (I95I).
} 
creases in merchandise costs. In several instances, therefore, OPS, upon approving an increase in manufacturers' prices, decided to permit distributors to pass-through only the absolute amount of such increase rather than to allow the usual percentage markup to be added. This was done, for example, in connection with soft-surface floor coverings and with automobiles.

Naturally, this policy evoked vigorous protests from the trades affected. As a direct result of these protests, Congress, in extending the Act in July, r95r, added the Herlong Amendment ${ }^{12}$ which required that all subsequently issued regulations provide for the maintenance of "customary percentage margins" for all distributors.

For the time being, previously issued regulations were unaffected but, as a result of continuing pressure, the renewal of the Act in the summer of $1952^{13}$ extended this requirement to all such regulations as well. The Amendment was, however, further modified to prohibit OPS from issuing or retaining in effect any regulation "which shall deny sellers of materials at retail or wholesale their customary percentage margins over costs of the materials or their customary charges" during the preKorean period. The addition of the phrase, "or their customary charges," appeared to confirm the OPS interpretation of the earlier amendment that it could continue requiring the use of dollars-and-cents margins in those trades where that practice had been customary.

Complying with this Congressional action, OPS promptly (Aug. 27, 1952) issued General Overriding Regulation $33,{ }^{14}$ permitting distributors to apply for relief if they believed that the regulations applicable to them did not comply with the new amendment. However, the change in the status of what had been a flexible administrative policy into a strict legal requirement led to considerable complications. It made it necessary for the agency to be prepared in each case to defend its regulatory margins as being at least equal to "customary percentage margins" or, where it could be demonstrated that these did not exist, as conforming to "customary charges."

This was often quite difficult. Even where the use of percentage margins was customary, it did not follow that "customary percentage margins" were readily determinable. Thus, a special survey of food distribution revealed very wide differences in the margins charged by the same kinds of stores for the same classes of commodities in the same or similar localities. Moreover, the use of different statistical techniques-each valid in principle-to determine the "customary" level yielded quite different results in practice. Controversy between the food trade and the agency with respect to whether its regulations conformed to the statutory requirement persisted until the end of the control program.

In short, OPS experience reinforced that of OPA in the conclusion that some form of margin control is the most appropriate technique for use in the regulation of prices charged by most retailers and wholesalers. It also shows, however, that

\footnotetext{
12 Supra, note 7 .

${ }^{13}$ Szspra, note 8.

I4 17 Fed. REg. 7852 (1952).
} 
this general technique cannot be applied in all cases and that there must be considerable administrative flexibility in adapting it to individual situations. Finally, the expression of such a general technique in the form of a specific statutory requirement raised very serious administrative difficulties, partly because the concept of "customary percentage margins" or even "customary charges" contained in the statute does not apply at all to many trades and is extremely difficult to define precisely in others.

\section{B. Imports}

The freeze also presented extremely urgent problems in connection with the prices of imported commodities. OPS had, of course, no direct control over the prices charged by foreign sellers. While it could limit the price paid by an American purchaser abroad, such authority would have been very difficult to exercise in the great bulk of cases. As far as the freeze was concerned, it limited only the prices charged in this country by resellers of imported goods.

Unlike the problems involved in distribution, OPA experience was of only limited value in relation to imports. In the first place, foreign trade in most basic commodities was under rigid international control during the war, both as to allocation and price. Second, the range of imports was greatly limited as a result of wartime conditions; thus, the normal flow of miscellaneous manufactured goods from Europe to the United States was almost completely cut off. Under OPS, in contrast, there were no international price controls, allocation controls were much more limited and less rigidly enforced, and the range of commodities to be dealt with was that normally encountered in peace time.

This does not mean that ceilings on the resale prices of imports could have no effect. In practice, the United States is so large a factor in many world markets that it could force foreign prices down in many cases by simply maintaining domestic resale ceilings. For many commodities, however, any such attempt to hold prices down would simply have resulted in the loss of needed supplies. Moreover, even where this danger did not exist, this power had to be used carefully in order to avoid creating serious ill will abroad. In fact, this problem of international relations could never be lost sight of in connection with import price control. This does not, of course, mean that the interests of some foreign countries in obtaining as high as possible a price for their exports to the United States could be regarded as overriding the basic stabilization objectives. On the other hand, it was equally clear that friendly relations could not be maintained if the legitimate interests of exporting countries were ignored.

This was recognized by the Office of Price Stabilization from the outset. Even before the GCPR was issued, officials of the ESA and State Department met with representatives of Latin American countries, explaining the need for initiating price controls and stating that, to the extent possible, these countries would be consulted with respect to actions which had a major effect on their interests. When the General Ceiling Price Regulation was being drafted, the agency consulted with 
the State Department with respect to the provisions dealing with imports. At the request of the Department, the following paragraph was included in the Statement of Considerations of the GCPR:

Opportunity will be afforded, through arrangements to be made by the Department of State, for consideration by the Director of Price Stabilization of the views of foreign governments regarding adjustments of ceiling prices of commodities which are of special concern to them.

While thus recognizing the broader aspects of the import problem, the direct job of OPS was price stabilization, and its top officials consequently were from the start advocates of a "tough" import price policy. However, virtually all other government agencies, for many different reasons, favored a more liberal policy, and in general OPS found itself unable to "hold-the-line" successfully.

Two general categories of imports can be distinguished. The first comprises the basic raw materials, including strategic items such as tin, chromium, and tungsten, and such essential civilian materials as coffee, wool, and wood pulp. The importance of these goods, and the very diverse considerations affecting each, made the development of any generally applicable standard impractical. A case-by-case approach was followed, under which what actually happened was that ceilings were generally raised-however reluctantly-wherever pressures were strong, while ceilings were maintained when there was little or no pressure on prices-that is, where prices would not have advanced significantly in any event. For only a few of these basic items, such as coffee, cocoa, and possibly wool, can it be said that ceilings effectively held down prices.

The second category includes the wide range of manufactured and semi-manufactured goods of all kinds, comprising many thousands of individual commodities. Here a case-by-case approach would have been impractical, and some general standard was essential. Following extensive inter- and intra-agency discussion, the General Import Regulation-CPR $3{ }^{x^{15}}$-was issued, applicable to virtually all manufactured goods as well as to some of the less important raw materials. This regulation permitted each importer to determine his ceilings on the basis of his current landed costs and his customary margins. The margins for importers who did not sell at retail were, however, determined on a dollars-and-cents rather than a percentage basis, both in order to minimize the inflationary impact and in the belief that this would induce importers to resist unnecessary price increases abroad. In the case of importing retailers, percentage margins were allowed.

The use of dollars-and-cents margins for other than importing retailers instead of percentage markups evoked substantial objection and controversy. Many importers argued that their costs of doing business had increased very substantially and that some costs, such as financing and commissions, varied directly with the cost of the imported product. They pointed also to the fact that a similar problem had arisen under OPA and that that agency had resolved the difficulty by permitting

15 16 FED. REg. 4184 (I95I). 
the use either of dollars-and-cents margins or of 75 per cent of the normal percentage margins, whichever was higher. For reasons which were never clearly stated, OPA precedent was not followed by OPS.

Pressure to modify the dollars-and-cents rule, at least to the extent allowed by $\mathrm{OPA}$, continued intensively after the regulation was issued..$^{16}$ To a considerable extent, however, this pressure seems to have been based more on issues of principle than on actual business hardship. As a practical matter, the general easing of world markets, coupled with the fact that the regulation had been somewhat loosely drawn, seems to have prevented any really serious problems from developing.

When the Herlong Amendment was made applicable in 1952 to all regulations previously issued, importers as well as other distributors were permitted to apply for relief under the provisions of GOR $23^{17}$ if they could show that they were unable to obtain their customary percentage margins under CPR-3r. As a result of the factors just described, however, little if any use appears to have been made of this relief by any importer or groups of importers.

Nevertheless, pressure to modify the regulation as a matter of principle continued and a proposed change was in the draft stage at the time all controls were terminated. Had world markets continued to rise, it seems highly probable that OPS would have been forced to modify its position much more promptly, perhaps along the lines of the OPA regulation, even in the absence of the Herlong Amendment. It is difficult, in fact, to defend on any purely logical basis the principle of limiting importers to their customary dollars-and-cents margins while permitting most other distributors, including importing retailers, to operate on the basis of percentage margins. There may, however, be cogent reasons for imposing some squeeze on importers' customary percentage margins as was done by OPA, but it would seem appropriate to give some recognition to the fact that a considerable part of the operating costs of many importers does vary with the landed costs of the products they handle.

\section{Manufacturing Industry}

The problems which confronted OPS as a result of the freeze in the broad field of manufacturing had no counterpart in OPA experience. The reasons for this have already been described. New ground had to be broken and new policies developed.

There were various possible ways in which the job of remedying price distortions in manufacturing industry could have been attacked. Theoretically, one possibility would have been to proceed immediately to the preparation and issuance of "tailored" regulations for each industry which would have established ceilings appropriate to each specific case. Unfortunately, there were two serious difficulties which made such a course appear impractical. In the first place, the agency staff was too small and many of them were too new and untrained to permit such a job

\footnotetext{
${ }^{10}$ This pressure came not only from the trade, but also through diplomatic channels. For example, on January I6, I952, Assistant Secretary of State Willard Thorp wrote Price Director DiSalle transmitting and in effect endorsing a communication from the British Embassy urging a change to the percentage margins basis.

${ }_{17}^{17} 6$ FED. REG. 12718 (195I).
} 
to be completed within a reasonable span of time. It seemed most unlikely that the tailoring process could proceed rapidly enough to cope with the large and increasing volume of complaints from industries and individual concerns that had been caught by the freeze in a seriously unfavorable position. Second, the problem of establishing appropriate price relationships between vertically related industries would have been very difficult to handle by treating each individual industry separately. For example, ceiling prices for apparel could not have been determined without reference to the levels for textiles; prices for consumers' durable goods would have depended upon the levels established for metals and parts; and prices for paper products upon the ceilings for pulp and paper. This would have meant, in effect, that definitive regulations for finished goods generally would have had to await the completion of regulations for raw materials and semi-manufacturers. This delay would have been particularly serious because it was precisely in the finished goods area that the pressures for adjustment were most acute.

In view of these considerations, it was decided that across-the-board action for most manufacturing industry was necessary. Accordingly, a group of regulations known as the "Manufacturers' Regulations" was issued, starting April 25, 1951. These included CPR 22 (the Manufacturers' General Ceiling Price Regulation), ${ }^{18}$ CPR 30 (Machinery and Related Manufactured Goods), ${ }^{19}$ CPR 37 (Primary Cotton Textile Manufacturers' Regulation), ${ }^{20} \mathrm{CPR} 4 \mathrm{I}$ (Shoe Manufacturers' Regulation), ${ }^{21}$ and CPR 45 (Apparel Manufacturers' General Ceiling Price Regulation). ${ }^{22}$ (CPR I8, Wool Yarns and Fabrics, ${ }^{23}$ which had been previously issued, was amended to conform with the same problem.) While these varied somewhat in detail, they all followed the general approach which had been incorporated in the Manufacturers' General Ceiling Price Regulation.

The principal features of this approach were as follows:

Each manufacturer was permitted to select as a "base period" for each category of commodities one of the four calendar quarters between July $\mathrm{r}, 1949$ and June $24,1950 .{ }^{24}$ For each commodity he then determined the highest price which he had charged during this base period and added to that price the increases in the costs of factory labor and purchased manufacturing materials which had occurred between the end of the base period and certain specified "cut-off" dates. Thus, in the case of labor, each manufacturer could take account of increases in factory labor costs up to March I5, I95I. As regards materials, a general distinction was made between those which were themselves subject to one of the manufacturers' regulations and those which were not. For most of the former, only those cost increases which had occurred up to December 3I, I950 could be taken into account; for most of the latter, increases through March 15 , 1951 could be included. This distinction was made because it was assumed that the operation of these regulations would result

\footnotetext{
${ }^{18}$ i6 Fed. REG. 3562 (195I). $\quad{ }^{18} I d$. at 4108 (195I). $\quad{ }^{20} I d$. at 4644 (1951).

${ }^{21}$ Id. at 5044 (195I). ${ }^{22}$ Id. at 5753 (I95I).

21 The last of these periods, namely, April $x$ to June 24, 1950, was, of course, six days short of a calendar quarter, but the June 24 date was used since it coincided with the Korean outbreak.
} 
in many rollbacks, particularly for materials in the early stages of fabrication, and that these rollbacks would result in a level of prices approximating that of December 3I rather than March I5.

These regulations, in effect, constituted the first important agency-wide standard of general applicability. Specifically, they established the following basic principles:

x. The agency refused to accept the validity of any price ceiling merely because it had been frozen under the GCPR and expressly undertook to roll back prices which had risen too rapidly while at the same time affording relief where needed.

2. In general, the ceiling price level appropriate for any manufacturing industry should be determined by adjusting its pre-Korean price level to take account of increases in direct costs up to certain specific cut-off dates.

3. By the same token, automatic, continued cost escalation was definitely rejected. In other words, the agency would not regard cost increases occurring after the specified dates as automatically entitling an industry to an equivalent increase in ceiling prices.

This explicit rejection of any form of automatic cost escalation was regarded as one of the most fundamental bulwarks of any effective price control program. The reasons for this were expressed as follows in the Statement of Considerations accompanying CPR 22:

\section{The Problem of Cost Absorption}

In adopting as its basic principle the adjustment of pre-Korean price levels to take account of the increase in manufacturing costs which has occurred since Korea, this regulation follows the only practicable method of restoring a balanced and generally equitable priçe structure that is available. This should not, however, be interpreted as constituting an acceptance or endorsement of the principle of automatic or indefinite cost escalation. It would be wholly unsound to base any continuing price control program or policy on the assumption that increases in costs should be automatically reflected in increases in price. This would result not in price control, but rather in rubber-stamped inflation.

No system of price control can do its job if each increase in costs is immediately and automatically translated into rising prices. Such a policy would leave us within the very same vicious circle of cost and price increases which it must be the primary object of any stabilization program to break.

Consequently, the cost-plus principle is incorporated in the present regulation only to a limited extent. It is used as the best available device for reestablishing a balanced and equitable price structure and should not be construed as implying any guarantee of profit levels. ...

It is particularly important to emphasize that this regulation allows only for past increases and carries with it no implication that increases which may occur subsequently will be treated on a similar automatic basis. . . . It is, of course, true that cost increases after March I5 are just as real as those which occurred before that date. However, as pointed out above, if price controls are to be real and not illusory, the cost-price cycle must be broken at some point. The cut-off date of March ${ }_{5}$ is one of the ways in which the break in this price-cost cycle must be accomplished. The date is, to some extent, arbitrary, but some date had to be set. . . .

It should be emphasized that selection of the March 15 date does not mean that cost 
increases after that date will be ignored. . . . If it should develop that for any industry, the ceilings calculated under this regulation do not satisfy the basic pricing standards shortly to be promulgated, the industry is invited to submit the facts necessary to demonstrate this condition. . . U. Upon a proper showing of facts, the Director is preparcd to take such action as is required to make the ceilings generally fair and equitable to each such industry....

The issuance of these regulations, together with other attempted rollbacks initiated by OPS, particularly in the field of livestock and beef generated a storm of protest from business. In view of the time needed by manufacturers to complete the fairly complex calculations required by these regulations, the effective date, originally set at May 28, I95I, was extended to July 2, I95I. As it happened, the original Defense Production Act expired on June 30 before Congress had been able to complete work on its extension. Consequently, an interim extension was approved by Congress but this specifically barred any rollback actions. When the Act was finally extended on July $3 \mathrm{r}$, I951, it included the so-called Capehart Amendment which made necessary a thorough re-examination of the policies contemplated in the Manufacturers' Regulations.

The text of this Amendment follows: $:^{25}$

Sec. $402(d)(4)$. After the enactment of this paragraph no ceiling price on any material (other than an agricultural commodity) or on any service shall become effective which is below the lower of (A) the price prevailing just before the date of issuance of the regulation or order establishing such ceiling price, or $(B)$ the price prevailing during the period January 25, r95 $\mathrm{x}$, to February 24 , r95 , inclusive. Nothing in this paragraph shall prohibit the establishment or maintenance of a ceiling price with respect to any material (other than an agricultural commodity) or service which ( $I$ ) is based upon the highest price between January I, 1950, and June $24,195^{\circ}$, inclusive, if such ceiling price reflects adjustments for increases or decreases in costs occurring subsequent to the date on which such highest price was received and prior to July 26, r951, or (2) is established under a regulation issued prior to the enactment of this paragraph. Upon application and a proper showing of his prices and costs by any person subject to a ceiling price, the President shall adjust such ceiling price in the manner prescribed in clause (I) of the preceding sentence. For the purposes of this paragraph, the term "costs" includes material, indirect and direct labor, factory, selling, advertising, office, and all other production, distribution, transportation and administration costs, except such as the President may determine to be unreasonable and excessive.

In effect, this Amendment did two things. With respect to all future regulations, it modified the formula incorporated in the Manufacturers' Regulations by changing the cut-off dates for both labor and materials to July 25, 1951, and by requiring the inclusion of all costs, including overhead, rather than merely direct manufacturing costs. Second, it entitled any manufacturer, whether or not subject to the Manufacturers' Regulations, to apply for individual ceiling price increases on the basis of this new formula.

It is important to emphasize, however, that the Capehart Amendment, in effect,

${ }^{25}$ Supra, note 6. 
gave explicit Congressional approval to the principle of a cut-off date and to the rejection of continued, automatic cost escalation. Consequently, it became possible for OPS to retain the principle of this essential standard for the remainder of the control program.

The amendment did, however, make it necessary for the agency to take a series of actions to implement its provisions. After some delay, reflecting uncertainty as to whether Congress would comply with the President's request to repeal the amendment, OPS decided that the only practical course was to amend the Manufacturers' Regulations to permit calculations to be made in accordance with the new formula as an alternative to the rules previously established. In reaching this conclusion, OPS was confronted with several important questions of policy. The first involved the decision as to whether the use of the Capehart formula should be an alternative to, or a mandatory substitute for, that prescribed in the original regulations. There were numerous cases in which costs as of July 26, I95I were lower than those on previously specified cut-off dates. In addition, increases in volume meant that overhead costs for many manufacturers, as of July 26 , were lower than they had been before Korea. Consequently, the mandatory application of the Capehart formula would have resulted in lower ceilings in a considerable number of cases than those originally provided. After considerable thought, however, OPS decided that it would be too much of a hardship to require manufacturers who had gone through the somewhat cumbersome calculations required in the original regulations, to scrap these and start all over again on a new basis. Consequently, it was decided to allow each manufacturer to choose between the two alternative methods.

The second major question arose because many manufacturers urged strongly that changes in overhead costs should be computed in terms of changes in the elements going into overhead only, without any allowance for the effect of changes in volume. This position was, of course, advanced most strongly by those industries whose production and sales had increased sharply since Korea. OPS, however, had little difficulty in reaching the conclusion that the Congressional intent, normal accounting practice, and the needs of sound administration all required that changes in volume must be included in the determination of unit overhead.

In addition to modifying the Manufacturers' Regulations, it was also necessary to issue regulations permitting other manufacturers to apply for individual adjustments as required by the third sentence of the amendment. The standards provided for these applications followed the same broad principles as those included in the amendments to the Manufacturers' Regulations.

At the time the Manufacturers' Regulations were issued, it had been contemplated that they would be essentially interim measures to be followed as rapidly as possible by tailored regulations for as many industries as possible. The uncertainties which followed the temporary extension of the Act and later the assessment of the impact of the Capehart Amendment, together with the possibility that the amendment might be modified, slowed this process very considerably. 
Until October, 195r, there were no explicit standards instructing officials as to the principles to be used in formulating tailored regulations, other than those implicit in the Manufacturers' Regulations themselves. On October 22, 195I, "Tentative Operating Instructions" were finally issued in the form of Price Operations Memorandum No. I3. This memorandum started by stating that "The program of OPS still gives highest priority to the preparation of tailored regulations." After describing the various forms which such tailored regulations could take, it set forth standards with respect to the levels to be established in such regulations.

POM I3 laid considerable stress on the desirability of providing rollbacks in tailored regulations-subject, of course, to the limitations imposed by the law and particularly by the Capehart Amendment. This emphasis on rollbacks, however, proved largely ineffective. It is difficult, in fact, to mention a single instance in which a tailored regulation issued subsequent to POM ${ }_{3}$ actually incorporated any significant rollback in accordance with these instructions. Both OPA and OPS experience has clearly demonstrated the extreme practical difficulties involved in rolling back price ceilings once they have been firmly established. Rollbacks had been difficult enough in the spring of I95I, though a limited number had been made effective; by the time POM I3 was issued, successful new rollbacks could scarcely be expected.

In the absence of any significant rollback actions, the principal issues encountered in the interpretation and application of the standards of POM $x_{3}$ focused on the methods to be used in establishing industry-wide ceilings for commodities under the GCPR and the Manufacturers' Regulations.

These arose in good part because the ceiling prices established for individual companies under the general regulations varied considerably. In some instances, the market situation was such that each company could actually realize its individual ceiling, but more commonly the companies with higher ceilings could not, in fact, obtain them. Often the lowest ceiling established for any substantial producer represented the effective ceiling for the entire industry. This was particularly true with respect to standard commodities, especially where there was normally a high degree of price uniformity, as in the case of tin cans or plate glass. OPS was under great pressure in such cases to establish a uniform ceiling on the basis of some sort of average of the ceilings for all producers. Ordinarily, this would have meant a substantial increase in the actual level of selling prices for the industry.

POM $x_{3}$ provided that ceilings in tailored regulations designed to replace those established under GCPR could be set on a weighted average basis. However, tailored ceilings, intended to supersede those calculated under the Manufacturers' Regulations, were to be set at the lowest level at which substantial volume occurred. There was considerable evidence that many of the ceilings individually established under the Manufacturers' Regulations were on the generous side and there were thus no a priori reasons for assuming that the lowest ceiling established for any substantial producer could not be regarded as equitable for the industry as a whole. 
Consequently, while this position was not universally adhered to, it was followed in the great majority of cases. A similar view, for essentially similar reasons, was taken with respect to ceiling prices established in conformity with the Capehart Amendment. Higher levels were granted only upon a showing that the industry was entitled to an increase under the earnings standard.

\section{Services}

In the broad field of services, it was believed impossible to handle the problems resulting from the freeze on the basis of any form of industry-wide action. Most services, and virtually all consumer services, represent essentially local industries, serving purely local markets and with cost structures reflecting largely local conditions. Even within any particular town or city there were often wide variations between the positions in which different service establishments of the same kind found themselves. The difficulties of the problem were accentuated by the fact that small establishments constituted a very large proportion of the membership of most service trades.

In view of these circumstances, the general policy adopted by OPS in this field was to permit individual service establishments to apply for adjustment of their ceiling prices whenever they could demonstrate substantial financial hardship. When CPR $34,{ }^{26}$ the general services regulation, was first issued on May II, I95I, the adjustment provision was very general in character and required a showing that the financial hardship was such as to threaten the applicant's ability to continue to supply the service, and also denied adjustments where an increase in the applicant's price would "create or tend to create a need for increases in the prices of other sellers. ..."

Since the Capehart Amendment applied to service establishments as well as to manufacturers and processors, it was necessary to modify this provision. Actually, the revised adjustment provision which was incorporated in Amendment 2 to Ceiling Price Regulation 34, dated January 9, $1952,{ }^{27}$ went considerably beyond the specific requirements of. the Capehart Amendment. It provided in general for the maintenance of the pre-Korean level of earnings, calculated as a percentage over operating costs, and it did not have any cut-off date.

The reasons for this considerably greater liberality were primarily related to the predominance of small business in most of the trades involved. Most of these smaller establishments did not maintain the kinds of records which would be needed for a precise application of the principles of the Capehart Amendment. In the case of manufacturing industry, the justification for ceiling price increases to take account of rising costs after July 26 , I95I, could be appraised in terms of the Industry Earnings Standard; for the service trades, such an approach would have been impractical and the delays involved in conducting industry earning surveys would have imposed serious hardship on small companies with limited resources.

20 I6 FED. REG. 4446 (195I).

${ }^{37}$ I7 FED. REG. 288 (r952). 


\section{Adjustment Standards}

One of the major problems of price regulation is that of determining when changes in established price ceilings must be made in order to preserve general fairness and equity, to relieve excessive individual hardship, or to avoid interfering with essential production. The rules under which such determinations can be made are among the most essential standards of any price control operation. The standards developed by OPS for this purpose included the Industry Earnings Standard, the Product Standard, the Essential Supply Standard, and provisions of the type included in General Overriding Regulation ro, ${ }^{28}$ which may be called the Individual Relief Standard. These were all patterned after similar rules which had been adopted by OPA.

\section{A. Relief of Individual Hardship}

Chronologically, the first of these problems to be handled was that of relieving cases of individual hardship in the field of manufacturing. When the General Manufacturers' Regulation (CPR 22) was issued on April 25, 195r, it included a provision permitting individual companies to apply for relief if, as a result of their ceiling prices, they would be operating at an over-all loss. The provision did not cover cases where such a loss was due to seasonal, non-recurring, or temporary factors; to reductions of production volume below normal economic capacity; to the payment of unlawful wages or salaries or excessive prices for materials; to abnormally high factory or general overhead costs; or to transactions with affiliated companies not resulting from arm's-length bargaining.

On May Ir, x951, General Overriding Regulation No. Io was issued which extended similar treatment to all manufacturers. The standard established for relief was the restoration of a break-even position, with the further restriction that the adjusted price level would not be substantially out of line with that of competing sellers.

On June $7, \mathrm{x} 95 \mathrm{I}$, this regulation was amended to permit adjustments to be made either for an entire company or for a separate plant or factory. ${ }^{20}$ On April 15, 1952, General Overriding Regulation No. Io was further modified. ${ }^{30}$ On the one hand, the requirement that the loss must not be due to reduction in volume below normal economic capacity was eliminated. At the same time, the regulation was changed to provide that the adjusted prices must be in line with those charged by competitors instead of "substantially in line." The purpose of the original restriction with respect to uneconomically low operation was to prevent abnormally high costs from being reflected in adjusted ceiling prices. However, according to the Statement of Considerations accompanying this Amendment, "adjustments based on abnormally high costs are restricted by the requirement that the adjusted ceiling price be in line. Since this 'in line' requirement is tightened by this Amendment, there is no further need for the limitation with regard to reduction in volume."

This relief provision was restricted to manufacturers. It was not needed in con-

${ }^{28}$ I6 Fed. ReG. 4455 (I95I). $\quad{ }^{20}$ Id. at 5478 (I95I).

${ }^{\text {so }} 77$ FED. REG. 3380 (1952). 
nection with service establishments because the General Services Regulation-CPR 34 -provided an adequate vehicle for handling problems arising in that field.

The application of a similar provision to distributors presented very serious practical difficulties. Moreover, the fact that distributors' prices were generally established on a margin basis meant that in the great majority of cases distributors' ceiling prices were reasonably in line with each other and this tended to reduce the need for and utility of this sort of hardship relief. Consequently, formulation of a comparable provision for distributors was delayed for a long time, and it was not finally issued until December I, I952, as General Overriding Regulation No. $40 .^{31}$

\section{B. The Industry Earnings Standard}

Probably the most important single OPS standard was the Industry Earnings Standard. This standard was designed to determine when and to what extent an industry-wide adjustment of ceiling prices was necessary in order to conform with the statutory requirement that ceiling prices must be "generally fair and equitable." On April 2r, I95r, Economic Stabilization Administrator Johnston sent a directive to Mr. DiSalle to the effect that ceiling prices should thereafter be adjusted only in accordance with the provisions of an earnings standard which he outlined. Under this standard, an industry would be entitled to increases in ceiling prices if and to the extent that its earnings fell below 85 per cent of their average level for the three best years out of the four year period, I946 through I949, adjusted for changes in net worth. OPS was instructed to prepare detailed rules for the application of this standard. Due largely to the extreme pressure of other work, however, these detailed rules were not actually promulgated until February 15, I952. In effect, this standard meant that an industry was not entitled to an increase in ceiling prices as long as its members remained, on the average, in the excess profits tax bracket. This was essentially the same policy as had been adopted by OPA and which had then been similarly related to the provisions of the wartime excess profits tax.

This standard was, from the start, under severe attack from many representatives of industry. This attack generally focused upon two points, one involving the general principles of any such standard, and the other, the specific form which this standard took.

The first and more general criticism was to the effect that the earnings standard constituted "profit control" and that the entire concept of requiring cost absorption was wrong in principle. As pointed out in the discussion of the Manufacturers' Regulations, however, there can be no effective price control if automatic cost escalation is permitted. On the other hand, it is equally clear that the ability of industry to absorb increased costs is limited. It is difficult to see how any objective test can be devised of the extent to which any industry can absorb cost increases without some reference to earnings.

Obviously, any form of price control must have an impact on profits. The Industry Earnings Standard, however, measured the need for price adjustment in

\footnotetext{
${ }^{32}$ Id. at 10860 (1952).
} 
terms of the experience of an entire industry. It did not, therefore, impair significantly the incentive to efficient operation for any individual company in that industry nor did it limit individual company profits except to the extent that they affected the industry aggregate.

The principal criticism of detail was that the standard referred to profits before taxes rather than profits after taxes. It was argued strongly that the concept of profits after taxes was unreal and that the only significant figure from the point of view of company operations was what was left after taxes had been paid.

The point was urged most emphatically by members of the steel industry in connection with the use of the Industry Earnings Standard as applied to the steel price-wage controversy during the spring of 1952 . In the same connection, the Industry Earnings Standard was severely criticized by the industry for the refusal to recognize accelerated amortization of facilities in so far as it exceeded normal rates of depreciation. Both these points are discussed at some length in another article in this series. ${ }^{32}$ For reasons set forth in that article, it seemed clear to OPS that these objections had no validity.

Despite these and other criticisms, therefore, the Office of Price Stabilization continued to apply the Industry Earnings Standard as its major test in determining the need for industry-wide price increases. It defended this standard before the committees of Congress when the Defense Production Act was up for renewal in 1952. In the face of considerable pressure from industry, Congress refused to take action that would require OPS to modify this standard. It may be added that a very similar OPA standard had been upheld by the courts as an appropriate method of determining whether ceiling prices were "generally fair and equitable."

The standard was, however, very severely tested following directives which were issued by the Director of Defense Mobilization to raise ceiling prices for steel and for copper wire and brass mill products by amounts substantially in excess of any that could be justified on the basis of industry earnings. The metal fabricating industries, notably machinery, argued that they, too, were entitled to more liberal treatment than that provided by the Industry Earnings Standard, both because they had to pay these higher prices for basic metals and because they were affected by the rapid spread of the wage increase pattern which had been set by steel. It was also urged that it was unfair to permit a breach of standards for a large and powerful industry such as steel but to maintain them firmly for smaller industries that were not able to exert similar economic and political pressure.

Despite the undeniable force of these contentions, OPS simply could not take the course of abandoning the earnings standard for the metal working industries. This was precisely the area in which price pressures were greatest and where controls seemed most needed at the time. It should be emphasized, moreover, that the price increases which had been granted to the steel and copper industries were allowed by OPS only on the basis of directives from higher government levels and

${ }^{32}$ See Wolf and Keller, Problems of the Industry Earnings Standard, infra, 581-603. 
that these directives explicitly provided for the maintenance of its standards in connection with further actions.

While the abandonment of the earnings standard would have been disastrous, particularly in the absence of any suitable substitute rule, equity still seemed to demand some relief for the metal working industries. After exploring a wide range of alternative possibilities, it was finally decided to take the relatively simple course of permitting the increases in metals' costs to be passed through by metal fabricators without absorption and also without escalation. At the same time, the agency reaffirmed its position that the earnings standard would continue to be applied to determine whenever other kinds of cost increases, such as wage boosts, required further adjustments in ceiling prices. Steps were also taken to expedite as far as possible the conduct of the surveys required to support such determinations.

With the exception of this metals "pass through," the Industry Earnings Standard remained to the end of the control period the basic working rule of the agency in determining the need for industry-wide price adjustments. Whether it should have been modified or supplemented in the light of prevailing conditions raises important questions which are discussed very briefly below.

\section{The Product Standard}

The earnings standard measured the adequacy of the general price level for an industry. It did not, however, take care of situations in which an individual product or product line might be unprofitable even though over-all industry earnings were adequate.

To take care of problems of this kind, OPA had adopted a standard which required that the price for each separate product or product line of an industry must be high enough to cover the out-of-pocket costs of the bulk of the producers. Difficulties with application of this standard led to its being modified by adoption of a working rule to the effect that the price must equal the weighted average of manufacturing costs.

The situation confronting OPS was somewhat different in this respect from that which had prevailed during wartime. The entire political and economic climate in I951 and 1952 made the adoption of the strict OPA rule seem impractical. Moreover, in the absence of the rigid wartime controls over production, manufacturers could much more readily shift out of lines on which the price covered no more than manufacturing costs without any allowance for such items as general overhead or sales expense.

Consequently, the OPS Product Standard, as issued on April 22, 1952, provided that prices for a product or product line would be adjusted when ceiling prices did not cover the weighted average total costs for all manufacturers producing that product.

At the time it was issued, it was not expected that this standard would be used extensively because it was anticipated that the Industry Earnings Standard would take care of most of the problems which might arise. This expectation was borne 
out in practice. There were very few cases in which the Product Standard as such was actually invoked. This was probably due to two principal reasons. In the first place, the prevalence of soft markets in a large sector of the economy meant that ceiling prices could not actually be realized for a wide range of goods, including almost all consumer soft goods and a large part of consumers' durables. Second, pressures were most acute in the field of metal products, but most of these could qualify for more liberal treatment under the Essential Supply regulation than under the Product Standard.

This does not mean that a Product Standard might not be needed under a condition of general inflationary pressure. The fact that it proved of very little value under OPS largely reflected the mixed economic situation which prevailed after the standard was issued.

\section{Essential Supply Standard}

Late in I95I, OPS was subjected to rapidly increasing pressure to provide a means for ensuring that price ceilings did not interfere with the production of commodities essential to the defense program or to the basic civilian economy. The great bulk of these pressures originated in the field of machinery and industrial metal products. The problems were generally of a kind which related to individual products or product lines rather than to the total operations of an industry. Moreover, the difficulties were frequently confined to single companies or groups of companies rather than to all the producers of the products in question.

Application of the Product Standard to situations of this kind could not meet the problem for two reasons. In the first place, as indicated above, the difficulties were often confined to one or a few producers. Second, since the Product Standard did not provide any profit margin, it could not prevent shifts of production. In this connection, it should be remembered that the Product Standard was based on the weighted average of the costs of all producers of the item so that some would still be selling the product at a loss.

In order to take care of situations of this kind, General Overriding Regulation 29 was issued on May 23, $1952 .{ }^{33}$ In effect, it provided a sort of combination of Earnings Standard and Product Standard relief on an individual company basis. Where the earnings of a company were more than 85 per cent of its average for its three most profitable years through $1946-1949$, the ceiling price for the product or product line in question would be adjusted to cover total costs. Where the rate of return was below that level, a normal rate of profit would be allowed.

The regulation also made even more liberal provision for items of outstanding importance to the defense program. In such cases, prices would be adjusted to provide a normal profit regardless of the over-all rate of return being earned by the company.

This standard was widely used and a large number of adjustments was granted under its provisions. In addition to individual adjustments granted under GOR 29,

${ }^{33}$ I7 FED. REG. 4762 (1952). 
the standards established in the regulation were also used in a number of special cases to grant industry-wide adjustments for products of outstanding essentiality. This was done, for example, in the case of aluminum and ferrochrome. While this way of applying the standard had not been contemplated at the time the regulation was written, such action conformed with the principles which had been established, and proved a useful means of dealing with what would otherwise have been very difficult situations.

\section{Decontrol and Suspension Standards}

In addition to standards needed for the administration of price controls, rules also had to be developed for determining when commodities or services should be exempted from controls or when ceilings should be suspended.

The techniques of exemption and suspension should not be confused since they were addressed to two different kinds of situations. In general, commodities or services were exempted from controls when the burden of retaining controls clearly outweighed any possible benefits to the stabilization program. The possibility that prices might rise above ceilings following exemption was therefore only a very secondary consideration. Suspension, on the other hand, was used where market prices were substantially below ceilings; where ceilings could not practically be reduced; and where there was little, if any, likelihood that prices would rise to or above ceilings. In other words, the principal consideration involved in exemption was the nature of the commodity or service concerned, whereas in suspension, it was the level of the established ceiling price as related to the realities of the market.

In the course of any program of general price control (as distinguished from selective control) it is necessary to determine which commodities, services, and sellers should be exempted. While no market transaction can be viewed in complete isolation, there are many whose impact on the broad objectives of any stabilization program are minuscule. Many other transactions, while of more individual importance, are still such that they do not warrant the administrative effort or the burden upon business which would be needed to control them effectively. There are still others whose nature is such that no practical means of effective control can be devised. Sound administration requires that transactions of this kind should be exempted. Such exemptions may relate to certain commodities or services or to certain classes of sellers.

Considerable care must be exercised, however, in formulating exemption policy. This is particularly true during periods of acute general inflationary pressure, when every business and every industry compete for the scarce supply of materials, manpower, and other resources. For example, it may be argued that luxuries, such as expensive fur coats, can safely be exempted regardless of the general situation and that uncontrolled price increases for such items would, in effect, be desirable since this would lessen the demand for more essential consumer goods. In a really tight situation, however, exemption of such luxuries from control would tend to divert 
needed resources to their production, though if pressures were milder and more spotty, exemption might be justified.

This danger is by no means theoretical. This may be illustrated by the curious case of Salt Flat Lake Herring which confronted OPS late in 1951. Prices paid by processors for the raw herring had risen substantially as a result of buying competition by mink farmers. Consequently, OPS found it necessary, on December 2I, I95I, to issue Ceiling Price Regulation I0 $^{34}$ raising the price of the processed herring, which was an important food item, particularly for low income families.

This sort of problem was, of course, exceptional. Under the economic conditions which prevailed during most of the life of OPS, a fairly liberal policy with respect to the exemption of luxuries was appropriate. In fact, it seems probable that the agency did not move rapidly enough in this direction.

Similarly, when the economic situation is such that competitive pressures are at least moderately effective, fairly generous small business exemptions can be safely granted on the assumption that, as long as larger companies are controlled, prices cannot get badly out of line. In a situation such as prevailed during the war, on the other hand, competition cannot be relied upon in this way and small business exemptions must be approached more cautiously.

This does not mean that there are not many cases in which exemptions are appropriate, regardless of the degree of inflationary pressure existing. For example, there is little point in expending administrative effort at any time on items of such very minor importance as hand decorated used bottles, or hand fans, or pincushions. The same is true of very small producers such as those engaged in homework industries. Nor can any effective control be exercised in some very important areas, such as the sale of farm produce by the farmer.

In the case of OPS, some exemptions were included in the General Ceiling Price Regulation itself and others followed shortly thereafter. The initial standards for exemption were contained in Price Operations Memorandum No. 5 which was issued on August 5, I95I. At the time, the general economic situation still seemed generally tight and the' standards were correspondingly rigid. They authorized exemption only in the case of materials and services which were "wholly insignificant" and then only if continuation of control would impose a significant burden on administration or business. Later, as the general situation eased, these standards were somewhat liberalized to permit, in effect, an appraisal of whether control imposed a burden on OPS or business "disproportionate in relation to the effectiveness of the control or the contribution to the price stabilization program."

In the field of small business, the GCPR itself contained certain very limited exemptions for homework industry; subsequent actions exempted manufacturers whose sales did not exceed $\$ 25,000$ annually. Serious consideration was given during 1952 to exempting a large number of smaller retailers and service establishments. While numerous proposals of this kind were drawn up, they had not yet been approved when the liquidation of controls was ordered by the President.

34 I6 FeD. REG. I287I (I95I). 
Whereas any price control program must consider the need for appropriate exemptions, OPS suspension policy was addressed to the specific conditions which prevailed during the latter part of the agency's life. It became evident late in I95I that market prices for many commodities were substantially below the price ceilings which had been established. Legislative restrictions and practical considerations precluded reducing ceilings to correspond with market conditions.

Consequently, during February, 1952, Price Director DiSalle appointed an ad hoc committee to develop standards for action in cases of this kind. The first such standard was issued on April 22, 1952, relating to raw materials, and on August 2I, 1952, it was expanded to include manufactured goods. In general, these rules provided that ceilings be suspended where prices were "materially below ceiling" and where there was "no prospect that re-imposition of controls would be necessary in the foreseeable future." The standard also provided that whenever a commodity was suspended, a "price watching system" should be established. The suspension was to be revoked whenever market prices rose toward the suspended ceilings and reached predetermined "trigger points" which were to be established at the same time as the suspension action. In fact, no suspensions ever had to be restored because of an advance of prices to the "trigger point." There was only one revocation of any suspension action, and that was for administrative reasons involving difficulty in defining the commodity area covered, coupled with adverse impact on the enforceability of a related regulation.

\section{Conclusions and Appraisai}

On the basis of actual experience, it may be concluded that the administrative standards used by OPS performed their necessary function reasonably well in most cases. It is equally clear, however, that this general conclusion must be subject to important reservations.

In the first place, economic trends during the life of OPS were such as to avert any really severe, comprehensive test of the standards. In those cases in which the standards were subjected to serious pressure, such as the steel, copper, and aluminum cases, the agency often had to accept a limited retreat. But despite these exceptions, OPS standards, once they were formalized, did generally serve their basic purpose of providing practical rules for consistent action.

Had inflationary pressure been stronger and more general, however, many of the standards would probably have proved untenable without major modification, unless other government controls had been sufficiently tightened to preserve a reasonably stable structure of costs. For example, it is doubtful that the Industry Earnings Standard could have been retained without important change as the basic rule for measuring the ability of industries to absorb cost increases. The large and rapidly increasing number of earnings standard cases which developed during the last half of 1952 subjected the standard to stresses for which it was not well designed. These stresses would obviously have been far greater had it not been for the prevalence of soft markets in a large part of the economy. 
It seems entirely probable, in fact, that if controls had not been permitted to expire early in 1953 , a general reappraisal and revision of the OPS hardship standards would have become necessary, despite the large areas of market softness. The test of a new wage increase for steel such as was agreed to in June, 1953, would have been very difficult to meet (unless, of course, wage controls had also been continued and could have succeeded in blocking that increase). Moreover, the growing number of industries which had received earnings standard adjustments would in general have had to be allowed to pass subsequent cost increases through, in full, and without any further absorption. To the extent this would have happened, the earnings standard would have been automatically transformed into a pass-through standard.

As mentioned earlier, OPS standards were in large part patterned after those. which had been employed by OPA, with modifications which were, on the whole, of relatively minor character. In retrospect, it would appear that sharper and bolder departures from the OPA pattern would have been appropriate, in view of the fundamental differences in economic and political conditions between the two periods.

In summary, just as OPA experience with administrative standards proved of great value to OPS, so the combined OPA-OPS experience should prove very useful if a price control program is again needed. However, OPS may have followed the general OPA line of policy too uncritically, and with inadequate adaptation to the basically different political and economic situation.

Advance planning for a possible future emergency should therefore stress the principle that administrative standards must take due cognizance of all elements of the environment in which they will operate, and must be subject to modification to conform with any radical changes in that environment. And the OPS experience clearly indicates that such advance planning is of the highest importance to ensure the maintenance of a consistent and effective program. 